\title{
TECHNOLOGY, DEVELOPMENT STATUS AND APPLICATIONS OF THE SHORT PULSES GYROTRON TRAVELING -WAVE-TUBE
}

\author{
Vinay Kumar \\ Electronics and Communication Engineering Department, \\ Institute of Engineering and Technology, Lucknow, India
}

\begin{abstract}
The gyrotron traveling-wave tube amplifier (gyroTWT) is mainly used as high power millimeter wave sources that addresses the well-known concept of the electron cyclotron maser (ECM) instability. This paper present technology, development status and application of the short pulses Gyro-TWT amplifiers over a long period of time. Mainly focused on the techniques, beam wave interaction structure, controlling instability, broadband operation, high-power, low magnetic field.
\end{abstract}

Keywords - high-order harmonic interaction, high-order mode interaction, bandwidth extending or broadband operation, waveguide wall loss. Electron cyclotron maser; gyrotron traveling-wave tube amplifier (gyro-TWT).

\section{INTRODUCTION}

Unlike linear beam tubes, gyro-devices employ an electron beam that consists of electronically accelerating electrons and the free energy remains in motion transverse in the applied magnetic field. In these devices, cyclotron resonances; (a new dimension in the interaction mechanism), permitting wave generation in simple and large-size as well as structures provides the physics underpinning. When the interaction involves the gyrational motion of electrons in a static magnetic field, the synchronism condition can be written as $\quad \omega-k_{z} \nu_{z}-s \Omega_{c} \cong 0$

Where, $(s=1,2, \ldots) \omega, k_{z}, v_{z}$ are the wave frequency, propagation constant and electron axial velocity respectively, $\left(k_{z} v_{z}=\right.$ doppler term) and $s, \Omega_{c}$ are the cyclotron harmonic number, and relativistic electron cyclotron frequency respectively. From equation (1) permits a simple fast- wave $\left(\omega / k_{z}>c\right)$ interaction structure.

In electron cyclotron masers electromagnetic energy is emitted by relativistic electrons rotating in an outward longitudinal magnetic field. In ECMs, the effective frequency $\Omega_{c}$ corresponds to the relativistic electron cyclotron frequency:

$$
\begin{aligned}
& \Omega_{c}=\Omega_{c 0} / \gamma \text { with } \Omega_{c 0}=e \mathrm{~B}_{0} / m_{0} \\
\text { and } \gamma & \gamma=\left[1-\left(\frac{v}{c}\right)^{2}\right]^{-\frac{1}{2}} \approx 1+\frac{\Theta v_{b}}{m_{0} c^{2}}=1+\frac{\theta b_{b}}{511}
\end{aligned}
$$

Where $\gamma$ is the relativistic Lorentz factor, $m_{0}$ is the mass of an electron, $e$ is the charge and $V_{0}, B_{0}$ are the acceleration voltage in $\mathrm{kV}$, magnitude of the guide magnetic field respectively.
The commercially available (the word record parameters) of maximum pulse is $140 \mathrm{GHz}, 0.92$ Mega-Watt-class gyrotrons using artificial diamond output power windows at 30 minutes pulse duration, $44 \%$ efficiency and $97.5 \%$ Gaussian mode purity. (CPI and European KIT-CRPP-TED (The Research University in the Helmholtz Association) collaboration). Employing a SDC (single-stage depressed collector) for energy recovery.

The JAEA-TOSHIBA $110 \mathrm{GHz}$ gyrotron generated a 1.5 MW output power (maximum) in 4.0 second pulse duration at $45 \%$ efficiency.

The maximum energy of 2.88 GJ (word record) in 60 minutes at 0.8 Mega-Watt was generated with the Japan 170 GHz ITER gyrotron, also achieved 1 Mega-Watt, 800 second pulse duration at $55 \%$ efficiency and the output power of greater than $0.5 \mathrm{MW}$ with the $57 \%$ efficiency record for tubes.

The Russian $170 \mathrm{GHz}$ ITER gyrotron generated 0.99 MegaWatt with a 1000 second pulse duration at $53 \%$ efficiency and also achieved 1.2 Mega-Watt with a 100 second pulse duration and $53 \%$ efficiency.

European $170 \mathrm{GHz}$ coaxial-cavity gyrotron (prototype tube) achieved of the $2 \mathrm{MW}$, in short pulses, 96\% Gaussian mode purity and $46 \%$ efficiency.

Numerous short-pulse applications, pulsed magnet with gyrotron achieved at frequencies up to $670 \mathrm{GHz}$ deliver 210 kilo-Watt in 20 second at $20 \%$ efficiency, $1 \mathrm{THz}$ deliver 5.3 kilo-Watt in at $6.1 \%$ efficiency and $1.3 \mathrm{THz}$ deliver 0.5 kiloWatt in 20 second at $0.6 \%$ efficiency.

In this paper section II gave the details review of technologies for experimental design of gyro-traveling wave tube amplifier. In section III shows the status of present development of gyro TWT in table form. In section IV conclusion and future of gyro-TWT and section $\mathrm{V}$ gives references.

\section{TECNOLOGIES FOR EXPERIMENTAL DESIGN OF GYRO- TWT}

In the prior gyro-TWT setups several types of interaction mechanism were applied Chu KR et al $(2002,2004)$. Each one setup discovered explanation to the problem to the of positive aspect. During these experiments time explore the key technology to developed and evaluate of the amplifier. For 


\section{International Journal of Engineering Applied Sciences and Technology, 2020 \\ Vol. 5, Issue 4, ISSN No. 2455-2143, Pages 571-578 \\ Published Online August 2020 in IJEAST (http://www.ijeast.com)}

better appreciate these technologies, make known to the problems introduce four characteristics, including 4 types of technology
A. high-order harmonic interaction,
B. high-order mode interaction,
C. bandwidth extending or broadband operation,
D. waveguide wall loss.

\section{A. High-order harmonic interaction:}

Developing and design of an experimental gyro TWT amplifier of a high-order harmonic is of great significance [Chu et al (2004)].

1. The harmonic number is inversely proportional to the magnetic field strength; Hence, the magnetic field intensity is reduced by harmonic interaction. As an example, developing Ka-band gyrotron amplifier for the application of military. Necessitates about 0.6 Tesla magnetic field strength for second harmonic structure. While only about 1.2 Tesla magnetic field strength necessitates the fundamental harmonic structure, and the first choice is superconducting magnet. For reducing the cost and improving the reliability on a normal coil used gyrotron amplifier.

2. The fundamental interaction coupling strength is greater than the operating mode, that while improve the threshold current of the total instability. Therefore, the device achieves stronger wave radiation power and may work at higher current [Wang QS , 1995].

3. Cyclotron beams (Large-orbit) with electron controlling center $r_{C}=0$ are recommended in a higher-order harmonic interaction structure. Thus, only for the modes with azimuthal index equaling to the cyclotron harmonic number, they have nonzero beam-wave coupling coefficient. Specifically, in a large-orbit interaction structure, $T E_{m n}$ mode $(m=s)$ can only successfully interact with the $s$ harmonic mode.

University of California Los Angeles (UCLA) [Furno DS, 1990] and University of California Davies (UC Davies) [Wang QS et.al, 1996] launched the experiments on harmonic Gyro-TWT amplifier. In 1990, the UCLA perform an experiment on hormonic gyrotron amplifier, that operated in $8^{\text {th }}$ harmonic. Circular waveguide and large orbit electron beam are used. The current, voltage and output power ware $150 \mathrm{~mA}, 350 \mathrm{kV}$ and $0.5 \mathrm{~kW}$ respectively. The efficiency of $\mathrm{Ku}$ band, gain and bandwidth ware $1.35 \%$, small signal $10 \mathrm{~dB}$, and $4.3 \%$ respectively.

In 1996, UC Davies using second harmonic gyro-TWT interaction carried out an experiment. The interaction circuit as shown in figure 1 was design as; an axial sliced circular waveguide, and four slices with $90^{\circ}$ interval along the axis.

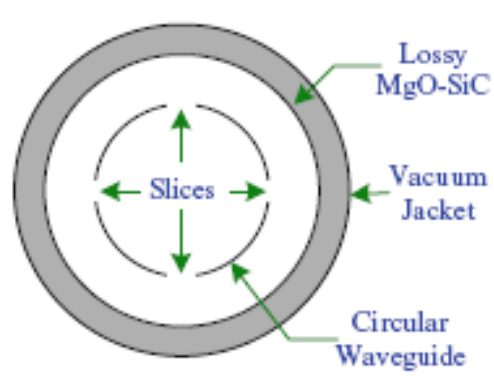

Figure 1: Sectional view of the sliced interaction waveguide. In this special structure, $T E_{n 1}$ mode ( $\mathrm{n}$ is odd) can be done efficiently the mode competition and scattered was also debilitated. The experiment structure utilized hormonic interaction and wall loss technology. The experiments effectively established that fundamental interactions ware less threshold current than hormonic interactions.

In 1998, UC Davies, also carried out an experiment using third harmonic gyro-TWT interaction experiments structure, X-band operated. The circuit as shown in figure 2 was a slotted waveguide: for the purpose of mode selection at intervals of $60^{\circ}$, six slots in waveguide wall along the axis. There were at intervals of $120^{\circ}$ also three slices that gave scattered loss. The device operating current and operating voltage are $8 \mathrm{~A}$ and $66 \mathrm{kV}$ respectively in $\pi$ mode with 1.05 velocity. Experimental device results show; $6 \mathrm{~kW}$ output power, $11 \mathrm{~dB}$ gain, $3 \%$ bandwidth and $5 \%$ efficiency.

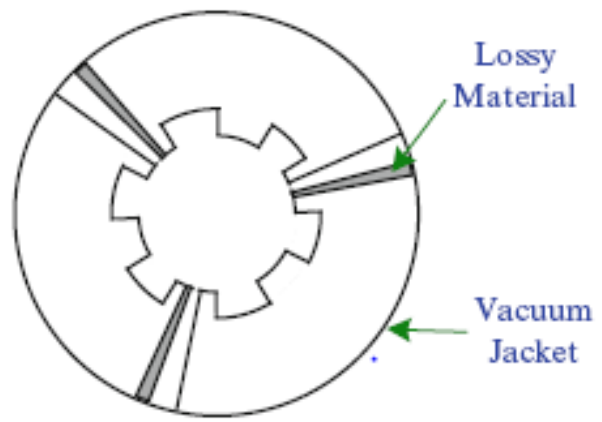

Figure 2: Sectional view of the slotted waveguide.

Theoretically we say that, a harmonic gyro-TWT provided higher output power and can operate on higher current. However, this is not always the result of the experiment. The magnetic field strength of the traditional system is several times greater than for harmonic operation. From lower-order harmonics, the mode competitions are unavoidable to encounter. Harmonic interaction system can be resolved all three issues of aspects:

1. To compress mode competition and to express the mode density through the suitable mode control mechanisms.

2. For improving the competing instability threshold current required to introduce appropriate lossy mechanism. Therefore, harmonic interaction systems were still very imperative subjects to resolve the mode competition and stability problem. 


\section{International Journal of Engineering Applied Sciences and Technology, 2020 Vol. 5, Issue 4, ISSN No. 2455-2143, Pages 571-578 \\ Published Online August 2020 in IJEAST (http://www.ijeast.com)}

3. To enhance the interaction efficiency, to increase the beam-wave coupling strength to adopt high voltage.

\section{B. High Order Mode Interaction Circuit:}

In Millimeter-wave band and beyond wave band the higher-order-mode interaction operation is the key reason that vacuum electronic devices based on ECM principle are capable of achieving higher output power than conventional VEDs. A high order mode improves the power capacity and interaction space. Still now, gyro-TWT experiments have $T E_{10}$ mode in rectangular waveguide [Park GS et al., 1995], $T E_{01}$ mode in cylindrical waveguide [Pershing DE et.al., and Nguyen KT et.al., 2004, 2001], $T E_{11}$ mode in cylindrical waveguide [Calame JP et al, and Garven $\mathrm{M}$ et al, 2002], $T E_{21}$ mode in cylindrical waveguide [Wang QS et al,1996], $T E_{11} / T E_{21}$ mode in helical corrugated waveguide [Bratman et al, and Denisov GG, 2000, 1998 ], $\pi$ mode in cylindrical waveguide with six azimuthal slots [Chong CK et al, 1998], and $H E_{06}$ mode in confocal waveguide. In other word say that gyro- TWT amplifiers works on higher order mode interaction low order modes as compare to gyrotron oscillator. In a gyroTWT experiment based on a confocal waveguide, MIT carried out on $140 \mathrm{GHz} H E_{06}$ mode with open side walls.

\section{Bandwidth Operation:}

Developing of gyro-TWT in its initial stage proved the advantage of broadband. Rectangular $T E_{10}$ mode waveguide gyro-TWT Ka-band tapered experiment was carried out [Park GS et al, 1994]; The output power and bandwidth ware $6.3 \mathrm{~kW}$ and $33 \%$ respectively with $10 \%$ efficiency and $16.7 \mathrm{~dB}$ gain. In another a later experiment, drifting waveguide divided the single stage tapered circuit into a double stage tapered circuit in the section of under-cutoff, toward both ends external tapered. The system was increased stability; however, there was still possibility of oscillation [Park GS et al, 1995]. The double tapered circuit experiment carried out; $8 \mathrm{~kW}$ output power, $16 \%$ efficiency, $25 \mathrm{~dB}$ gain and $20 \%$ bandwidth. Even through the circuit increase the bandwidth.

University of California, Los Angeles (UCLA) in the middle of 1990s [Rao SJ et al, 1996], using dielectric-loaded rectangular waveguide, X-band gyro-TWT experiment carried out, output power and gain ware $55 \mathrm{~kW}$ and $27 \mathrm{~dB}$ respectively with $11 \%$ bandwidth and efficiency. To improve results another more experiments done [ Rao SJ et al (1996), Cross AW (2007), Guo H et al,(1982) ].

Cooperation with Russia Institute of Applied Physics (IAP) and University of Strathclyde, Glasgow, UK developed for broad band operation [Denisov GG et al, 1998] helical corrugated waveguide based gyro-TWT amplifier works on a coupled mode and is capable of broadband operation. Since 1998, helical corrugated waveguide based experiments are continue study by University of Strathclyde and IAP. Early experiment was X-Band based on second hormonic interaction with $200 \mathrm{kV}$ voltage and $25 \mathrm{~A}$ current it carried out $1 \mathrm{MW}$ output power, greater than $10 \%$ bandwidth ,23 dB gain and $20 \%$ efficiency. An improve experiments setup carried out output power, relative bandwidth and gain were 1.1 MW, 21\% and $37 \mathrm{~dB}$, respectively.

In 2002 another Ka-band experiment generate using voltage $80 \mathrm{kV}$ and current $20 \mathrm{~A}$ (large orbit electron beam), it generates output peak power $180 \mathrm{~kW}$, bandwidth $10 \%$ gain 27 $\mathrm{dB}$ and efficiency $27 \%$. In 2007 using a electron beam another X-band experiment of current $6 \mathrm{~A}$ and voltage 185 $\mathrm{kV}$, it carried out output power $185 \mathrm{~kW}$, bandwidth $2 \mathrm{GHz}$ and gain $24 \mathrm{~dB}$. Helical corrugated waveguide based gyro-TWT amplifier has advantages from two characteristics:

1. It operates on coupled mode; $k_{z} \approx 0$, with small propagation constant closed to region. Which makes it insensitive to the propagation of the electron beam.

2. The harmonic operation magnetic field strength is basically much lower than the conventional harmonic scheme.

\section{Waveguide Wall Loss}

Until now, the waveguide wall loss is the most successful solution to suppress the instability competition problem in gyro-TWTs. By loading a certain kind of wave dissipating material is realized the waveguide wall loss, during its propagation on the magnificent a distributed loss and waveguide wall consequence to wave mode, while find the negligible disturbance to the operating mode supply.

In American NRL early 1980s revealed a series of experiments in that the interaction circuits loaded with distributed waveguide wall loss were accomplished of increasing the stability and gain of a gyro-TWT [LauYY et al $(1981,1982)]$. To base on the distributed wall loss interaction circuit, firstly operated in $\mathrm{Ka}$ band gyro-TWT, mode interaction is $T E_{01}$ with $3 \mathrm{~A}$ beam current, it carried out linear gain of $50 \mathrm{~dB}$ and pitch factor 1.5, [Barnett et al, 1980].

Prof. K. R. Chu and his group in 1990s [Chu Kr, et al, (1995, 1998, 1999, 2002, 2004] based strong theoretical backup, achieved a series of Ka-band gyro-TWT experiments. In 1998, designed gyro-TWT experiment TE11 mode Ka band fundamental harmonic, it generates gain up to $70 \mathrm{~dB}$ (ultrahigh) output peak power $93 \mathrm{~kW}$ and efficiency $26.5 \%$. Noted that threshold current was improved 0.9A to 3.5 A.

In 1996 UCLA achieved Ku-band gyro-TWT as shown in figure 1 . It operated at $T E_{21}$ mode of second hormonic with pitch factor 1.1 , current $20 \mathrm{~A}$ and electron beam voltage $80 \mathrm{kV}$. The experiment carried out peak power $207 \mathrm{~kW}$, bandwidth $2.1 \%$, gain $16 \mathrm{~dB}$ and efficiency $12.9 \%$. From above waveguide wall loss technique review, it concluded that; in a gyro-TWT appreciate several ways :

* utilizing quasi-optical confocal waveguide with partial open boundary

* using ceramic-loaded cylindrical waveguide 


\section{International Journal of Engineering Applied Sciences and Technology, 2020 \\ Vol. 5, Issue 4, ISSN No. 2455-2143, Pages 571-578 \\ Published Online August 2020 in IJEAST (http://www.ijeast.com)}

* including lossy material filled sliced waveguide

* including coating lossy material on the inner wall of the waveguide

* using loading low conductivity material in the linear stage of the circuit

waveguide wall loss can be resolved all these issues are summarized as:

1. When the frequency becomes nearer to the cut-off frequency, then the wall loss inflicts to a mode much stronger attenuation, therefore occurs typically selfexciting oscillation.

2. The reflected wave in a lossy interaction system toward upstream end through the loss circuit travels inversely, so the downstream port has much stronger attenuation. Therefore, the driving power promises stable operation and the initial non-bunched cyclotron beam perform little influence in the input stage.
3. The wall-loss technique has the skill of suppressing the mode competition and selectively attenuation, and thus to suppress instability competition of gyroTWTs can be usually applied the wall losses technique.

\section{PRESENT DEVELOPMENT STATUS OF SHORT PULSE GYROTRON TRAVELING WAVE TUBE}

The next generation of high-energy physics accelerators and the next frontier in understanding of elementary particles is based on supercolliders. Such generators are also required for atmospheric sensing and super-range high-resolution radar. Therefor Table 1 gives an overview of the present development status of short pulse relativistic gyrotron travelling wave tube (Gyro-TWT) amplifiers.

Table 1; Present Development Status of Short Pulse Relativistic Gyrotron Traveling Wave Tube.

\begin{tabular}{|c|c|c|c|c|c|c|c|}
\hline Institution & Mode & $\begin{array}{l}\text { Frequency } \\
(\mathrm{GHz})\end{array}$ & Power (kw) & $\begin{array}{c}\text { Bandwidth } \\
(\%)\end{array}$ & Gain $(\mathrm{dB})$ & $\begin{array}{l}\text { Efficiency } \\
(\%)\end{array}$ & Type \\
\hline \multirow{3}{*}{$\begin{array}{l}\text { BVERI, Beijing } \\
{[32-34]}\end{array}$} & $T E_{02}$ & 34.2 & 290 (5av.) & 8.0 & 65 & 34 & periodic $\mathrm{SiC}$ loading \\
\hline & $T E_{02}$ & 48 & 150 (5av.) & 7.0 & 50 & 35 & periodic SiC loading \\
\hline & $T E_{02}$ & 95 & 120 & 6.3 & 39 & 32 & periodic $\mathrm{SiC}$ loading \\
\hline \multirow{4}{*}{$\begin{array}{l}\text { CPI, Palo Alto [35- } \\
40]\end{array}$} & $T E_{21}$ & 5.18 & 120 & 7.3 & 20 & 26 & MIG \\
\hline & $T E_{12}$ & 5.2 & 64 & 7.3 & 17.5 & 14 & Pierce-helix gun \\
\hline & $T E_{12}$ & 63.7 & 28 & 2 & 31 & 7.8 & Pierce-helix gun \\
\hline & $T E_{02}$ & 95 & 1.5 (0.6av.) & 7.7 & 42 & 4.2 & Pierce-helix gun \\
\hline $\begin{array}{c}\text { EEV, Chelmsford } \\
\text { [41] }\end{array}$ & $T E_{22} / T E_{+12}$ & $10\left(2 \Omega_{z}\right)$ & 180 & -- & $-\overline{-}$ & $\begin{array}{l}-- \\
\end{array}$ & gridded gun \\
\hline \multirow[t]{4}{*}{$\begin{array}{c}\text { IAP, Nizhny } \\
\text { Novgorod [42-45] }\end{array}$} & $T E_{22} / T E_{+12}$ & $36.3\left(2^{\Omega_{z}}\right)$ & 180 & 10 & 25 & 27 & $\begin{array}{l}\text { cusp gun with axis-encircle. } \\
\text { Beam } 3 \mu \mathrm{s}\end{array}$ \\
\hline & \multirow[t]{3}{*}{$T E_{22} / T E_{+12}$} & \multirow[t]{3}{*}{$34.3\left(2 \Omega_{z}\right)$} & 120 & 6 & 20 & 23 & long pulse $110 \mu \mathrm{s}$ \\
\hline & & & 160 & 1.3 & 27 & 36 & $250-\mu$ s pulse $(\mathrm{CW})$ \\
\hline & & & 7.7 & 7.5 & 27 & 33 & \\
\hline \multirow{2}{*}{$\begin{array}{l}\text { IECAS, Beijing [46- } \\
48\end{array}$} & $T E_{12}$ & 16.2 & 130 & 12.3 & 41 & 17.8 & periodic lossy \\
\hline & $T E_{22}$ & 34.5 & 110 & 5 & 33 & 15.2 & periodic lossy \\
\hline \multirow{3}{*}{$\begin{array}{c}\text { MIT, Cambridge } \\
{[49-52]}\end{array}$} & $H E_{061}$ (q.o.) & 140 & 30 & 1.6 & 29 & 12.5 & \multirow{3}{*}{$\begin{array}{l}\text { at } 0.875 \mathrm{~kW} 400 \mathrm{ps} \text { modulation } \\
\text { pulse } \mathrm{PBG}, 260 \mathrm{ps} \text { pulses }\end{array}$} \\
\hline & & & .0 .55 & 0.9 & 35 & 0.4 & \\
\hline & $T E_{02}$ (like) & 250 & 0.045 & 3.2 & 38 & 0.4 & \\
\hline \multirow{5}{*}{$\begin{array}{l}\text { NRL, Washington } \\
\text { D.C. [53-54] }\end{array}$} & $T E_{10}$ & 32.5 & 6.3 & 33 & 16.7 & 10 & 1-stage tapered \\
\hline & $T E_{10}$ & 35.5 & 8 & 20 & 25 & 16 & 2-stage tapered \\
\hline & $T E_{10}$ & 32.3 & 50 & 11 & 25 & 28 & $\begin{array}{l}\text { folded waveguide } \\
\text { axis-encircle Beam }\end{array}$ \\
\hline & $T E_{02} / T E_{12}$ & 34.0 & 137 & 3.3 & 47 & 17 & 2-stage output \\
\hline & $T E_{02} / T E_{12}$ & 35.6 & 70 & 17 & 60 & 17 & 2-stage output \\
\hline \multirow{5}{*}{$\begin{array}{l}\text { UC Los Angeles / } \\
\text { Davis [55-57] }\end{array}$} & $T E_{18}$ & 9.3 & 55 & 11 & 27 & 11 & diel. coat. waveguide \\
\hline & $T E_{21}$ & $10.4\left(3 \Omega_{z}\right)$ & 6 & 3 & 11 & 5 & axis-encircle. beam \\
\hline & $T E_{22}$ & $15.7\left(2 \Omega_{z}\right)$ & 207 & 2.1 & 16 & 12.9 & slotted waveguide \\
\hline & $T E_{n 2}$ & $16.2\left(8 \Omega_{z}\right)$ & 0.5 & 4.3 & 10 & 1.3 & axis-encircle. beam \\
\hline & $T E_{02}$ & 92 & 140 & 2.2 & 60 & 22 & $\begin{array}{l}\text { heavily loaded }+ \\
\text { short copper stage }\end{array}$ \\
\hline \multirow{3}{*}{$\begin{array}{c}\text { NTHU, Hsinchu } \\
{[58-59]}\end{array}$} & $T E_{21}$ & 35.8 & 27 & 7.5 & 35 & 16 & 2-stage severed \\
\hline & $T E_{12}$ & 34.2 & 62 & 12 & 33 & 21 & 2-stage lossy (short) \\
\hline & $T E_{12}$ & 33.6 & 93 & 8.6 & 70 & 26.5 & 2-stage lossy (long) \\
\hline \multirow{4}{*}{$\begin{array}{l}\text { UESTC, Chengdu } \\
{[60-64]}\end{array}$} & $T E_{12}$ & 16 & 200 (20 av.) & 16.3 & 43 & 23.8 & 3-stage lossy (long) \\
\hline & $T E_{02}$ & 16 & 420 & 10 & 35 & 23 & periodic lossy circuit \\
\hline & $T E_{02}$ & 34 & 165 (11.5 av.) & 10 & 45 & 27.5 & lossy circuit \\
\hline & $T E_{92}$ & 48 & 158 & 7 & 47 & 22.6 & periodic lossy circuit \\
\hline
\end{tabular}


International Journal of Engineering Applied Sciences and Technology, 2020

Vol. 5, Issue 4, ISSN No. 2455-2143, Pages 571-578

Published Online August 2020 in IJEAST (http://www.ijeast.com)

\begin{tabular}{|c|c|c|c|c|c|c|c|}
\hline & $T E_{02}$ & 92.5 & 110 & 4.2 & 69.2 & 19.3 & lossy circuit \\
\hline $\begin{array}{c}\text { University } \\
\text { Kwangwoon [65] }\end{array}$ & $T E_{10}$ & 14.4 & 14.9 & 7 & 27 & 18 & two-stage circuit \\
\hline $\begin{array}{c}\text { University } \\
\text { Strathclyde [66-69] }\end{array}$ & $T E_{-22} / T E_{+12}$ & $93\left(2 \Omega_{s}\right)$ & 3.4 & 5.8 & 37 & 4.2 & cusp gun with axis-encircle beam \\
\hline $\begin{array}{c}\text { University Tel Aviv } \\
\text { [70] }\end{array}$ & $T E_{10}$ & 7.3 & 0.8 & & 26 & 12 & 3 -stage output \\
\hline
\end{tabular}

\section{CONCLUSION}

In this paper we have described technology issues and experimental setup or physics of the gyro-devices along with worldwide research highlights of these issues. An overview survey shows Gyro-TWT as a practical millimeter wave band and beyond one of the most promising devices of high-power generator, broadband operation, and high gain. It is revealed that gyro-TWT amplifiers are have mostly problems in developing of high power correlated to the uncertainty competition.

\section{REFERENCE}

[1] Chu KR (2004) The electron cyclotron maser. Rev Mod Phys 76:489-540

[2] Chu KR (2002) Overview of research on the gyrotron traveling-wave amplifier. IEEE Trans Plasma Sci 30:903-908

[3] Wang QS, Mcdermott DB, Luhmann NC (1995) Demonstration of marginal stability theory by a 200kW 2nd-harmonic gyro-TWT amplifier. Phys Rev Lett 75:4322-4325

[4] Furuno DS, Mc dermott DB, Kou CS et al (1990) Operation of a large-orbit high-harmonic gyrotraveling-wave tube amplifier. IEEE Trans Plasma Sci 18:313-320

[5] Wang QS, McDermott DB, Luhmann NC (1996) Operation of a stable 200-kW second harmonic gyroTWT amplifier. IEEE Trans Plasma Sci 24:700-706.

[6] Park GS, Choi JJ, Park SY et al (1995) Gain broadening of 2-stage tapered gyrotron traveling wave tube amplifier. Phys Rev Lett 74:2399-2402

[7] Pershing DE, Nguyen KT, Calame JP et al (2004) A TE11 Ka-band gyro-TWT amplifier with highaverage power compatible distributed loss. IEEE Trans Plasma Sci 32:947-956

[8] Nguyen KT, Calame JP, Pershing DE et al (2001) Design of a Ka-band gyro-TWT for radar applications. IEEE Trans Electron Devices 48:108115

[9] Calame JP, Garven M, Danly BG et al (2002) Gyrotron-traveling wave-tube circuits based on lossy ceramics. IEEE Trans Electron Devices 49:14691477.

[10] Garven M, Calame JP, Danly BG et al (2002) A gyrotron-traveling-wave tube amplifier experiment with a ceramic loaded interaction region. IEEE Trans Plasma Sci 30:885-893
[11] Wang QS, McDermott DB, Luhmann NC (1996) Operation of a stable 200-kW second harmonic gyroTWT amplifier. IEEE Trans Plasma Sci 24:700-706.

[12] Bratman VL, Cross AW, Denisov GG et al (2000) High-gain wide-band gyrotron traveling wave amplifier with a helically corrugated waveguide. Phys Rev Lett 84:2746-2749

[13] Denisov GG, Bratman VL, Cross AW et al (1998) Gyrotron traveling wave amplifier with a helical interaction waveguide. Phys Rev Lett 81:5680-5683

[14] Chong CK, McDermott DB, Luhmann NC (1998) Large-signal operation of a third-harmonic slotted gyro-TWT amplifier. IEEE Trans Plasma Sci 26:500-507

[15] Park GS, Park SY, Kyser RH et al (1994) Broad-band operation of a Ka-band tapered gyrotraveling wave amplifier. IEEE Trans Plasma Sci 22:536-543

[16] Park GS, Choi JJ, Park SY et al (1995) Gain broadening of 2-stage tapered gyrotron travelingwave tube amplifier. Phys Rev Lett 74:2399-2402

[17] Leou KC, McDermott DB, Luhmann NC (1996) Large-signal characteristics of a wide-band dielectricloaded gyro-TWT amplifier. IEEE Trans Plasma Sci 24:718-726

[18] Rao SJ, Jain PK, Basu BN (1996) Broadbanding of a gyro-TWT by dielectric-loading through dispersion shaping. IEEE Trans Electron Devices 43:2290-2299

[19] Rao SJ, Jain PK, Basu BN (1996) Two-stage dielectric-loading for broadbanding a gyro-TWT. IEEE Electron Device Lett 17:303-305

[20] Cross AW, HeW, Phelps ADR et al (2007) Helically corrugated waveguide gyrotron traveling wave amplifier using a thermionic cathode electron gun. Appl Phys Lett 90:253501

[21] Guo H, Chen L, Keren H et al (1982) Measurement of gain for slow cyclotron waves on an annular electron beam. Phys Rev Lett 49:730-733

[22] Denisov GG, Bratman VL, Phelps ADR et al (1998) Gyro-TWT with a helical operating waveguide: new possibilities to enhance efficiency and frequency bandwidth. IEEE Trans Plasma Sci 26:508-518

[23] Lau YY, Barnett LR, Granatstein VL (1982) Gyrotron traveling wave amplifier: IV. Analysis of launching losses. Int J Infrared Millim Waves 3:4562

[24] Lau YY, Chu KR, Barnett LR et al (1981) Gyrotron traveling wave amplifier: I. Analysis of oscillations. Int J Infrared Millim Waves 2:373-393 


\section{International Journal of Engineering Applied Sciences and Technology, 2020 \\ Vol. 5, Issue 4, ISSN No. 2455-2143, Pages 571-578 \\ Published Online August 2020 in IJEAST (http://www.ijeast.com)}

[25] Lau YY, Chu KR, Barnett LR et al (1981) Gyrotron traveling wave amplifier: II. Effects of velocity spread and wall resistivity. Int $\mathbf{J}$ Infrared Millim Waves 2:395-413

[26] Lau YY, Chu KR (1981) Gyrotron traveling wave amplifier: III. A proposed wideband fast wave amplifier. Int J Infrared Millim Waves 2:415-425

[27] Barnett LR, Baird JM, Lau YY et al (1980) A high gain single stage gyrotron traveling-wave amplifier. Int Electron Devices Meet 26:314-317

[28] Chu KR, Barnett LR, Chen HY et al (1995) Stabilization of absolute instabilities in the gyrotron traveling-wave amplifier. Phys Rev Lett 74:11031106

[29] Chu KR, Chen HY, Hung CL et al (1998) Ultrahigh gain gyrotron traveling wave amplifier. Phys Rev Lett 81:4760-4763

[30] Chu KR, Chen HY, Hung CL et al (1999) Theory and experiment of ultrahigh-gain gyrotron traveling wave amplifier. IEEE Trans Plasma Sci 27:391-404

[31] Sirigiri JR, Shapiro MA, Temkin RJ (2003) Highpower 140-GHz quasioptical gyrotron traveling-wave amplifier. Phys Rev Lett 90:258302

[32] Wang, E.F., Zeng, X., Liu, B.T., Li, Z.L., Feng, J.J., Yan, T.C., (2013), Experimental study of high frequency and high-gain Ka-band gyrotron-traveling wave-tube. Proc. 14th IEEE Int. Vacuum Electronics Conference (IVEC 2013), Paris, France, 3P-15.

[33] Liu, B., Li, Z.,Wang, E., Zeng, X. Zhu, Y., Feng, J., Yan, T., (20130, Experimental study of a Q-band gyro- TWT. Proc. 14th IEEE Int. Vacuum Electronics Conference (IVEC 2013), Paris, France, 7A-5.

[34] Wang, E., Xi, A., Zeng, X., Sun, H., Zhu, S., Feng, J., (2015), Preliminary experiment research on the Wband gyrotron traveling wave tube. 16th IEEE International Conference on Vacuum Electronics (IVEC 2015), Beijing, P.R. China, S7.4.

[35] Blank, M., Borchard, P., Cahalan, P., Cauffman, S., Chu, T.S., Felch, K., Jory, H., (2005), High-power gyrotron oscillator and broadband gyro-amplifier development at CPI. Proc. 6th Int. Workshop on Strong Microwaves in Plasmas, Vol. 1, 46-57.

[36] Blank, M., Borchard, P., Cauffman, S., Felch, F., (2006), Broadband W-band gyrotron amplifier development. Conf. Digest 31st Int. Conf. on Infrared and Millimeter Waves and 14th Int. Conf. on Terahertz Electronics, Shanghai, China, 198.

[37] Ferguson, E., Symons, R.S., (1981), A gyro-TWT with a space-charged limited gun. Proc. Int. Electron Device Meeting, 198-201.

[38] Eckstein, J.N., Latshaw, D.W., Stone, D.S., (1983), $95 \mathrm{GHz}$ gyro traveling wave tube. VARIAN Assoc., Final Rep. Contract DASG60-79-C-005 MOD P003
(BMDACTC), and Bohlen, H.P., Felch, K., 1996, private communication, CPI, Palo Alto.

[39] Blank, M., Borchard, P., Cauffman, S., Felch, K., (2005), Development and demonstration of a broadband W-band gyro-TWT amplifier. Conf. Digest 30th Int. Conf. on Infrared and MillimeterWaves and 13th Int. Conf. on Terahertz Electronics, Williamsburg, VA, USA, 652-653.

[40] Blank, M., Borchard, P., Cauffman, S., Felch, K., (2006), Demonstration of a broadband W-band gyroTWT amplifier. Proc. Int. Vacuum Electronics Conference and Int. Vacuum Electron Sources (IVEC/IVESC 2006), Monterey, California, USA, 459-460.

[41] Duffield, M.J., North, R., (2011), Manufacture and evaluation of a GyroTWA amplifier. Proc. 12th IEEE Int. Vacuum Electronics Conf. (IVEC 2011), Bangalore, India, pp. 333.

[42] Samsonov, S.V., Gachev, I.G., Denisov, G.G., Bogdashov, A.A., Mishakin, S.V., Fiks, A.S., Soluyanova, E.A., Tai, E.M., Dominyuk, Y.V., Levitan, B.A., Murzin, V.N., (2014), Ka-Band gyrotron traveling-wave tubes with the highest continuous-wave and average power. IEEE Trans. on Electron Devices, 61, No. 6, 4264-4267.

[43] Samsonov, S.V., Denisov, G.G., Gachev, I.G., Bogdashov, A.A., Mishakin, S.V., Fiks, A.S., Soluyanova, E.A., Tai, E.M., (2014), Ka-band gyroTWTs with high CW and average power. Proc. 9th Int. Workshop "Strong Microwaves and Terahertz Waves: Sources and Applications", Nizhny Novgorod, Russia, pp. 172-173.

[44] Samsonov, S.V., Bogdashov, A.A., Denisov, G.G., Gachev, I.G., Mishakin, S.V., (2016), Recent experiments and simulations on gyro-TWTs with helically corrugated waveguides. Proc. 41 st Int. Conf. on Infrared, Millimeter and Terahertz Waves (IRMMW-THz 2016), September 25-30, Copenhagen, Denmark, H4B.5.

[45] Samsonov, S.V., Denisov, G.G., Gachev, I.G., Bogdashov, A.A., Mishakin, S.V., Manuilov, V.N., Belousov, V.I., Sobolev, D.I., Sokolov, E.V., Soluyanova, E.A., Tai, E.M., (2017), Development of gyrotron traveling-wave tubes at IAP and Gycom. EPJ Web of Conferences, 149, 04002 (2 pp).

[46] Cooke, S.J., Cross, A.W., He, W., Phelps, A.D.R, (1996), Experimental operation of a cyclotron auto resonance maser oscillator at the second harmonic. Phys. Rev. Lett., 77, 4836-4839.

[47] Young, A.R., He, W. Ronald, K., Cross, A.W., Whyte, C.G., Phelps, A.D.R., (1998), Cold and thermionic cathode CARM experiments. Conf. Digest 23rd Int. Conf. on Infrared and Millimeter Waves, Colchester, UK, 448-449. 


\section{International Journal of Engineering Applied Sciences and Technology, 2020 \\ Vol. 5, Issue 4, ISSN No. 2455-2143, Pages 571-578 \\ Published Online August 2020 in IJEAST (http://www.ijeast.com)}

[48] Felch, K., James, B.G., Borchard, P., Cahalan, P., Chu, T.S., Hargreaves, T.A., Blank,M., Pershing, D.E., Calame, J.P., Nguyen, K., Danly, B.G., Levush, B., (1999), Recent test results for a $10 \mathrm{kWaverage}$ power W-band gyroklystron amplifier. Conf. Digest 24th Int. Conf. on Infrared and MillimeterWaves,Monterey, California, USA, M-A5.

[49] Nanni, E.A., Jawla, S., Lewis, S.M., Shapiro,M., Temkin, R.J., (2016), Amplification of picosecond pulses with a photonic-band-gap gyro-TWT. 17th IEEE International Vacuum Electronics Conference (IVEC 2016), April 19-21, Monterey, CA, USA, Invited Keynote, S8.4.

[50] Soane, A.V., Shapiro, Jawla, S,M.A., Temkin, R.J., (2017), Operation of a 140-GHz gyro-amplifier using a dielectric-loaded, sever-less confocal waveguide. IEEE Trans. on Plasma Science, 45, No. 10, 28352840.

[51] Soane, A.V., Jawla, S., Shapiro, M.A., Temkin, R.J., (2017), A $140 \mathrm{GHz}$ gyro-amplifier using a dielectricloaded, sever-less confocal waveguide. Proc. 18th IEEE Int. Vacuum Electronics Conference (IVEC 2017), London, UK, GIII-2.

[52] Nanni, E.A., Jawla, S., Lewis, S.M., Shapiro, M.A., Temkin, R.J., (2017), Photonic-band-gap gyrotron amplifier with picosecond pulses. Appl. Phys. Lett., 111, 233504 (5 pp).

[53] Calame, J.P., Garven, M., Danly, B.G., Levush, B., Nguyen, K.T., (2003), Gyrotron-traveling wave-tube circuits based on lossy ceramics. IEEE Trans. on Electron Devices, 49, 1469-1477.

[54] Pershing, D.E., Nguyen, K.T., Calame, J.P., Danly, B.G., Levush, B., Wood, F.N., Garven, M., (2004), A TE11 Ka-band gyro-TWT amplifier with highaverage power compatible distributed loss. IEEE Trans. On Plasma Science, 32, 947-956.

[55] Chong, C.K., McDermott, D.B., Luhmann, Jr., N.C., (1998), Large-signal operation of a third-harmonic slotted gyro-TWT amplifier. IEEE Trans. on Plasma Science, 26, 500-507.

[56] Song, H.H., McDermott, D.B., Hirata, Y., Barnett, L.R., Domier, C.W., Hsu, H.L., Chang, T.H., Tsai, W.C., Chu, K.R., Luhmann, Jr., N.C., (2004), Theory and experiment of a $94 \mathrm{GHz}$ gyrotron traveling-wave amplifier. Physics of Plasmas, 11, 2935-2941.

[57] Barnett, L.R., Luhmann, N.C., Jr., Chiu, C.C., Chu, K.R., Yan, Y.C., (2007), Advances in W-Band TE01 gyro-TWT amplifier design, Proc. 8th IEEE Int. Vacuum Electronics Conference (IVEC 2007), Kitakyushu, Japan, 233.

[58] Barnett, L.R., Tsai, W.C., Hsu, H.L., Luhmann, Jr., N.C., Chiu, C.C., Pao, K.F., Chu, K.R., (2006), 140 kWW-band TE01 ultra high gain gyro-TWT amplifier. Proc. Int. Vacuum Electronics Conference and Int. Vacuum Electron Sources (IVEC/IVESC 2006), Monterey, California, USA, 461-462.

[59] Chiu, C.C., Pao, K.F., Yan, Y.C., Chu, K.R., Barnett, L.R., Luhmann, N.C., (2008), Nonlinearly driven oscillations in the gyrotron traveling-wave amplifier, Proc. 33rd Int. Conf. on Infrared, Millimeter and Terahertz Waves, Pasadena, CA, USA, T5D23.1185.

[60] Wang, J., Tian, Q., Li, X., Shu, G., Xu, Y., Luo, Y., (2017), Theory and experiment investigate of a 400 kW Ku-band gyro-TWT with mode selective loss loading structure. IEEE Trans. on Electron Devices, 64, 550-555.

[61] Xu, Y., Li, Y.,Wang, J., Jiang,W., Liu, G., Luo, Y., Li, H., (2018), Design and Experiment of a high power and broadband Ku-band TE11 Mode GyroTWT. IEEE Trans. on Electron Devices, 65, No. 5, 1962-1968.

[62] Yan, R., Luo, Y., Zhang, Q., Shang, Y., Liao, X., (2018), Development of high average power and high stability gyro-TWT for industrial use. Proc. 19th Int. Vacuum Electronics Conference (IVEC 2018), Monterey, CA, USA, 8.4.

[63] Yan, R., Li, H., Wang, D., Wang, J., Wang, L., Pu, Y., Xu, Y., Jiang, W., Liu, G., Luo, Y., (2018), Investigation on high average power operations of gyro-TWTs with dielectric-loaded waveguide circuits. IEEE Trans. on Electron Devices, 65, No. 7, 3012-3018.

[64] Jiang, W., Wang, J., Shen, Y., Liu, G., Wu, Z., (2018), Curved geometry collector design for highpower gyrotraveling wave tubes. IEEE Trans. on Electron Devices, 65, No. 6, 2327-2333.

[65] Jung, S.W., Lee, H.S., Jang, K.H., Choi, J.J., So, J.H., (2015), Experiments on a Ku-band gyrotron traveling-wave-tube amplifier with a tapered waveguide. J. Korean Phys. Soc., 67, No. 5, 854-859.

[66] He, W., Donaldson, C.R., Zhang, L., McElhinney, P., Yin, H., Ronald, K., Cross, A.W., Phelps, A.D.R.,(2015), Latest envelopment of a W-band gyro-TWA based on a helically corrugated interaction region. $16^{\text {th }}$ IEEE International Conference on Vacuum Electronics (IVEC 2015), Beijing, P.R. China, S7.1.

[67] Phelps, A.D.R., (2017), Progress in microwave to sub-THz sources at Strathclyde. EPJ Web of Conferences, 149, 04023 (2 pp).

[68] He,W., Donaldson, C.R., Zhang, L.,McElhinney, P., Garner, J., Ronald, K., Cross, A.W., Phelps, A.D.R., (2017), Measurement of a W-band gyro-TWA experiment based on a helically corrugated interaction region. Proc. 18th IEEE Int. Vacuum Electronics Conference (IVEC 2017), London, UK, GIII-6.

[69] He, W., Donaldson, C.R., Zhang, L., McElhinney, Yin, H., P., Garner, J., Ronald, K., Cross, A.W., 
International Journal of Engineering Applied Sciences and Technology, 2020

Vol. 5, Issue 4, ISSN No. 2455-2143, Pages 571-578

Published Online August 2020 in IJEAST (http://www.ijeast.com)

Phelps, A.D.R., (2017), Design and experiment of a broadband W-band gyro-TWA mbased on a helically corrugated interaction region. Proc. 42nd Int. Conf. on Infrared, Millimeter, and Terahertz Waves (IRMMW-THz 2017), Cancun, Mexico, RC2.4.

[70] Kesar, A., Blank, D., Jerby, E., (2002), Amplitude locking in a gyro TWT amplifier with a delayed feedback. 29th IEEE Int. Conf. on Plasma Science (ICOPS 2002), Banff, Canada, May 26-30, 3P18. 